\title{
Selvmordsrisiko hos personer med somatiske lidelser
}

\author{
Av Ping Qin
}

MANGE AV OSS vil, på et eller annet tidspunkt, få en alvorlig fysisk sykdom. Både sykdom og sykdomsbehandling kan påvirke hvordan vi tenker og føler. Alvorlig fysisk sykdom kan gripe inn i livet på mange måter, og påvirkningen kan bli kronisk. Noen mennesker klarer ikke å leve med alvorlig sykdom og velger å dø ved selvmord. Fysiske sykdommer er vanlige i befolkningen. Derfor kan fysisk sykdom være et viktig bidrag til selvmordsforekomst i et samfunnsperspektiv, spesielt blant eldre.

Selvmord som opptrer i forbindelse med alvorlig fysisk sykdom, manifesterer seg muligens i noen grad klinisk forskjellig fra øvrige selvmord. For eksempel er tradisjonelle risikofaktorer som psykisk lidelse og rusmisbruk i familien muligens til stede i mindre grad. Det er også sannsynlig at noen risikofaktorer for selvmord er potensielt unike eller spesifikke ved fysisk sykdom. Formålet med denne artikkelen er å gi en narrativ oppsummering av sammenhengen mellom fysisk sykdom og selvmordsrisiko med hensyn til spesifikke diagnoser, alvorlighetsgrad, tid, komorbiditet av flere fysiske sykdommer og i nærvær av psykiske lidelser (Ping Qin, 2016).

\section{Selvmordsrisiko ved fysisk sykdom og spesifikke diagnoser}

I internasjonal litteratur pekes det ofte på at fysiske sykdommer spiller en rolle ved $20-40 \%$ av alle selvmord. En dansk landsomfattende studie viste at
$64 \%$ av personer som døde av selvmord hadde minst én sykehusinnleggelse for fysisk sykdom før vedkommende begikk selvmord, og at pasienter som hadde vært innlagt på grunn av fysisk sykdom hadde mer enn dobbelt så høy risiko for senere selvmord enn personer av samme alder og kjønn, men uten fysisk sykdom (P. Qin, Webb, Kapur, \& Sorensen, 2013).

Omfattende epidemiologiske studier har vist at det er økt risiko for selvmord i forbindelse med en rekke alvorlige fysiske sykdommer, slik som kreft (Allebeck, Bolund, \& Ringback, 1989; Fang et al., 2012; Hem, Loge, Haldorsen, \& Ekeberg, 2004; Storm, Christensen, \& Jensen, 1992; Vyssoki et al., 2015), diabetes mellitus (Tseng, 2004), epilepsi (Christensen, Vestergaard, Mortensen, Sidenius, \& Agerbo, 2007), multippel sklerose (Bronnum-Hansen, Stenager, Nylev, \& KochHenriksen, 2005; Fredrikson, Cheng, Jiang, \& Wasserman, 2003), hjerneslag (Eriksson, Glader, Norrving, \& Asplund, 2015; Teasdale \& Engberg, 2001), hierteinfarkt (Larsen, Agerbo, Christensen, Sondergaard, \& Vestergaard, 2010), traumatisk hierneskade (Wasserman et al., 2008) og HIV/AIDS (Jia, Mehlum, \& Qin, 2012). Det er også andre studier som viste en høyere risiko for selvmord eller selvmordsatferd hos pasientene ved andre fysiske sykdommer, f.eks. Huntingtons sykdom (Paulsen, Hoth, Nehl, \& Stierman, 2005), Parkinsons sykdom (Stenager, Wermuth, Stenager, \& Boldsen, 1994), leddgikt (Timonen et al., 2003), allergi (P. Qin, Mortensen, Waltoft, \& Postolache, 2011), kronisk 


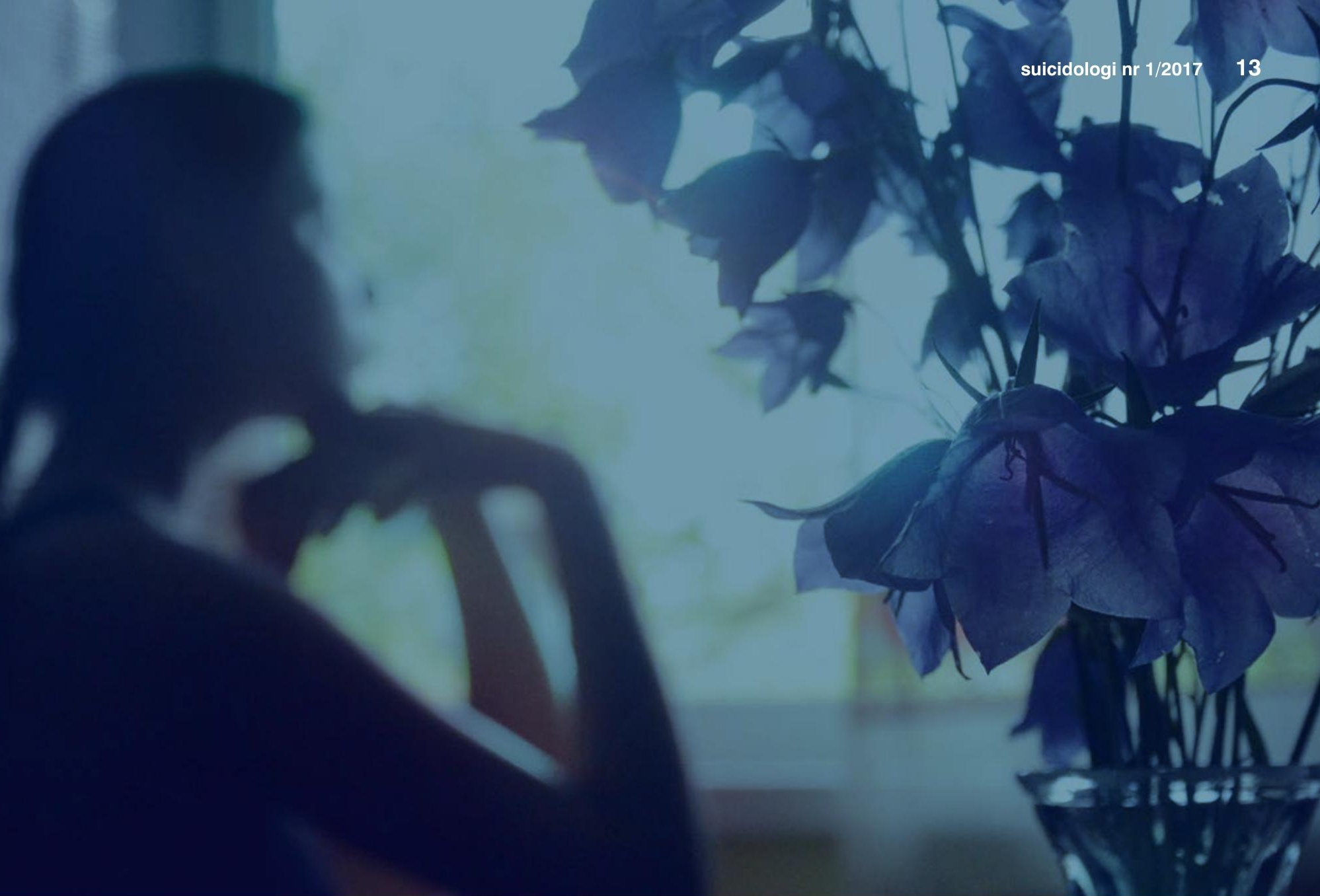

obstruktiv lungesykdom (kols) (Strid, Christiansen, Olsen, \& Qin, 2014) og inflammatorisk tarmsykdom (Gradus et al., 2010). Tabell 1 viser selvmordsrisikoen ved noen vanlige fysiske sykdommer basert på resultater fra storskala epidemiologiske studier av personer i alle aldre.

Mens de fleste studier har undersøkt selvmord ved en bestemt fysisk sykdom eller en generell sykdomstilstand, har noen få storskalastudier undersøkt selvmordsrisiko på tvers av en rekke fysiske forhold samtidig i én befolkning. En studie med data fra en allmennmedisinsk forskningsdatabase i Storbritannia viste at blant alle pasienter

Det er verdt å merke seg at selvmordsrisikoen knyttet til en fysisk sykdom kan endre seg over tid som var i kontakt med fastlege, var koronar hiertesykdom, hierneslag, kronisk obstruktiv lungesykdom og osteoporose assosiert med forhøyet selvmordsrisiko (Webb et al., 2012). En annen studie som brukte data fra danske landsomfattende registre viste at sammenlignet med personer uten sykehusinnleggelse for fysisk sykdom, var det hos sykehusinnlagte pasienter en betydelig okt risiko for selvmord forbundet med spesifikke sykdommer i alle organer eller organsystemer (P. Qin et al., 2013). Ulike spesifikke sykdommer økte selvmordsrisikoen fra to til fire ganger, med stor variasion fra sykdom til sykdom slik en ser i Tabell 1. Studien viste også markante kjønnsvariasjoner, og generelt økte selvmordsrisikoen mer hos kvinner enn hos menn (P. Qin et al., 2013).

Blant eldre er det høyere forekomst av selvmord og fysiske sykdommer. Eldre som tar sitt liv og samtidig har somatiske sykdommer, kan bli registrert som døde av somatiske sykdommer i stedet for av selvmord. Likevel er det godt dokumentert at det er en sterk sammenheng mellom fysisk sykdom og selvmord blant eldre. En systematisk oversiktsartikkel som undersøkte sammenhengen mellom fysisk sykdom eller funksionshemning og selvmordsatferd blant personer over 65 år, viste at selvmordsatferd var sterkt assosiert med funksionshemning og en rekke spesifikke sykdommer, herunder blant annet ondartede sykdommer, nevrologiske lidelser, smerte, kronisk obstruktiv lungesykdom, leversykdom og leddgikt (Fassberg et al., 2015).

Det er verdt å merke seg at selvmordsrisikoen knyttet til en fysisk sykdom kan endre seg over tid. En norsk studie av selvmord blant pasienter med kreft viste en tydelig nedadgående trend i selvmordsfare hos personer med slik diagnose fra 1960- til 199o-årene for begge kiønn (Hem et al., 2004). For kvinner i denne studien var det ikke noen signifikant høyere selvmordsrisiko enn i tilsvarende gruppe av befolkningen i den siste tiårsperioden (Hem et al., 2004). En dansk studie av pasienter med AIDS viste også en mindre sterk effekt av sykdommen på selvmordsrisiko etter innføringen 
av den høyaktive antiretroviralbehandlingen (Jia et al., 2012). Dette er sannsynligvis eksempler på effekter av forbedringer i den somatiske behandlingen av sykdommer og kanskje også den psykososiale oppfølgingen av pasienter med alvorlig sykdom.

\section{Alvorlighetsgrad, tid og komorbiditet}

Forverring av somatisk sykdom svekker ofte pasientens fysiske funksion, livskvalitet så vel som psykiske velvære, og kan dermed forsterke pasientens ønske om å ta eget liv. Spesielt er det $ø$ kt risiko hvis pasienten får økende eller mer kroniske smerter, eller dersom funksionsnivået og pasientens autonomi svekkes. Flere studier har dokumentert en økning av selvmordsrisiko knyttet til alvorlighetsgraden av fysiske sykdommer. Selvmordsrisikoen oker ytterligere ved forverring av sykdomstilstanden (Hem et al., 2004; Paulsen et al., 2005; Vyssoki et al., 2015). Dette er særlig tydelig for sykdommer som kreft der risikoen for selvmord ikke er betydelig okt ved lokalisert sykdom (kreft i stadium 1), men den øker til over fire ganger så høy risiko hvis kreften har spredt seg til andre steder i kroppen (kreft i stadium 4) (Hem et al., 2004; Vyssoki et al., 2015). Dette er også tydelig for tilstander med flere sykehusinnleggelser (Christensen et al., 2007; Fredrikson et al., 2003; P. Qin et al., 2011; P. Qin et al., 2013).

Mange studier har vist at perioden umiddelbart etter at man har fått diagnosen er mest kritisk for selvmord, særlig ved alvorlige sykdommer. For eksempel, selvmordsrisikoen blant pasienter med kreft var over 15 ganger så høy i det første året etter å ha blitt diagnostisert i en studie fra Sverige som fokuserte på perioden før 1979 (Allebeck et al., 1989). En senere svensk studie som fokuserte på perioden 1991-2006 viste en 12 ganger høyere risiko for selvmord i løpet av den forst uken etter å ha fått en kreftdiagnose, selv om risikoen i det første året var 3 ganger høyere (Fang et al., 2012). For mange pasienter kan det i den første tiden etter at diagnosen er stilt være vanskelig å akseptere at de er alvorlig syke. Så kan selvmordsrisikoen bli lavere med tiden inntil tilstanden eventuelt blir klart forverret. Andre kritiske perioder er tiden omkring innleggelse i sykehus og de første dagene etter utskrivning (P. Qin et al., 2013). Som vist i Figur 1 fra en dansk studie, er selvmordsrisikoen høyest under innleggelse og i den første uken etter utskrivning fra siste sykehusinnleggelse og reduseres gradvis med tiden (Figur 1). Vi har ikke noen tilsvarende studie fra Norge, men sannsynligvis er selvmordsfaren like stor under sykehusinnleggelse her på grunn av lignende sosiale strukturer som i Danmark. Selv om det er vanskelig å klarlegge hvilken innflytelse per se det er av å bli innlagt på sykehus (sykehusinnleggelse kan i seg selv indusere stress hos pasientene), er det trolig at den akutte og forverrede tilstand av sykdommen og påkjenningene ved å vende tilbake til det vanlige liv i samfunnet bidrar til høyere risiko for selvmord i denne perioden.

Mennesker som dør av selvmord har gierne flere sykdommer samtidig (komorbiditet). Den danske studien viste at $36 \%$ av dem som døde av selvmord hadde vært innlagt i sykehus for sykdommer som forekommer i mer enn ett organ eller organsystem, sammenliknet med $18 \%$

TABELL 1. Selvmordsrisiko assosiert med noen vanlige fysiske sykdommer

\begin{tabular}{|l|l|l|}
\hline $\begin{array}{l}\text { Fysisk sykdom } \\
\text { Enhver fysisk sykdom }\end{array}$ & $\begin{array}{l}\text { Assosiert selvmordsrisiko } \\
(95 \% \text { konfidensintervall) }\end{array}$ & Kilde \\
\hline Kreft & $2,1(2,1-2,2)$ & Qin et al., 2012 (P. Qin et al., 2013) \\
\hline Diabetes mellitus & $1,6(1,4-1,7)$ for menn; 1,4 (1,2-1,6) for kvinner & Hem et al., 2004 (Hem et al., 2004) \\
\hline Multippel sklerose & $1,6(1,6-1,7)$ & Tseng et al., 2004 (Tseng, 2004) \\
\hline Epilepsi & $2,4(1,6-3,8)$ & Fredriksson et al., 2003 (Fredrikson et al., 2003) \\
\hline Hjerteinfarkt & $3,2(2,9-3,5)$ & Christensen et al., 2007 (Christensen et al., 2007) \\
\hline Hjerneslag & $3,3(1,6-6,6)$ & Larsen et al., 2010 (Larsen et al., 2010) \\
\hline Osteoporose & $1,9(1,7-2,1)$ for menn; 1,8 (1,5-2,1) for kvinner & Teasdale et al., 2001 (Teasdale \& Engberg, 2001) \\
\hline Kronisk obstruktiv lungesykdom & $2,6(2,3-2,8)$ & Webb et al., 2012 (Webb et al., 2012) \\
\hline Allergi & $1,6(1,4-1,8)$ & Strid et al., 2014 (Strid et al., 2014) \\
\hline Ulcerøs kolitt & $1,9(1,4-2,4)$ & Qin et al., 2011 (P. Qin et al., 2011) \\
\hline HIV/AIDS & $3,8(2,5-5,8) ;$ & Gradus et al., 2010 (Gradus et al., 2010) \\
\hline
\end{tabular}

Forsiktighet må utvises ved sammenligning av estimatene på grunn av forskjellige referansegrupper. 
i kontrollgruppen (P. Qin et al., 2013). Selvmordsrisikoen okte med antall sykdommer som involverte flere organer eller organsystemer. Det var et signifikant dose-responsforhold som vist i Figur 2. De sterkt forhøyede risikoene knyttet til komorbiditet av flere sykdommer ble i stor grad redusert når dataene ble justert for psykisk og sosioøkonomisk status. Likevel var økningen i selvmordsfare fortsatt fremtredende for begge kjønn sammenlagt, og for menn og kvinner hver for seg.

\section{Påvirkningen av komorbide psykiske lidelser}

Ved somatiske sykdommer er det økt forekomst av psykiske lidelser, særlig angst og depresion. En studie fra Storbritannia rapporterte at blant mennesker som døde av selvmord og hadde somatisk sykdom, hadde mer enn $40 \%$ også en klinisk depresion (Webb et al., 2012). En studie fra Danmark viste videre at blant pasienter som hadde tatt livet sitt og som hadde en fysisk sykdom, hadde over $45 \%$ også hatt sykehusbehandling for psykiske lidelser før selvmordet, og $28 \%$ av disse menneskene hadde utviklet psykisk lidelse etter at de fikk den fysiske sykdommen (P. Qin, Hawton, Mortensen, \& Webb, 2014). Fysisk syke personer som døde ved selvmord var særlig utsatt for å utvikle stemningslidelser, primært depresion, eller for å få en rusmisbrukslidelse (P. Qin et al., 2014).

Ettersom psykisk lidelse er den sterkeste risikofaktoren vi kienner for selvmord, kan effekten av fysisk sykdom på selvmordsrisiko bli betydelig økt ved psykiatrisk komorbiditet. Det er også som forventet at selvmordsrisikoen forbundet med fysisk sykdom ofte blir redusert når effekten av psykiske lidelser

\section{FIGUR 1. Selvmordsrisiko i forhold til tid siden siste sykehusinnleggelse}

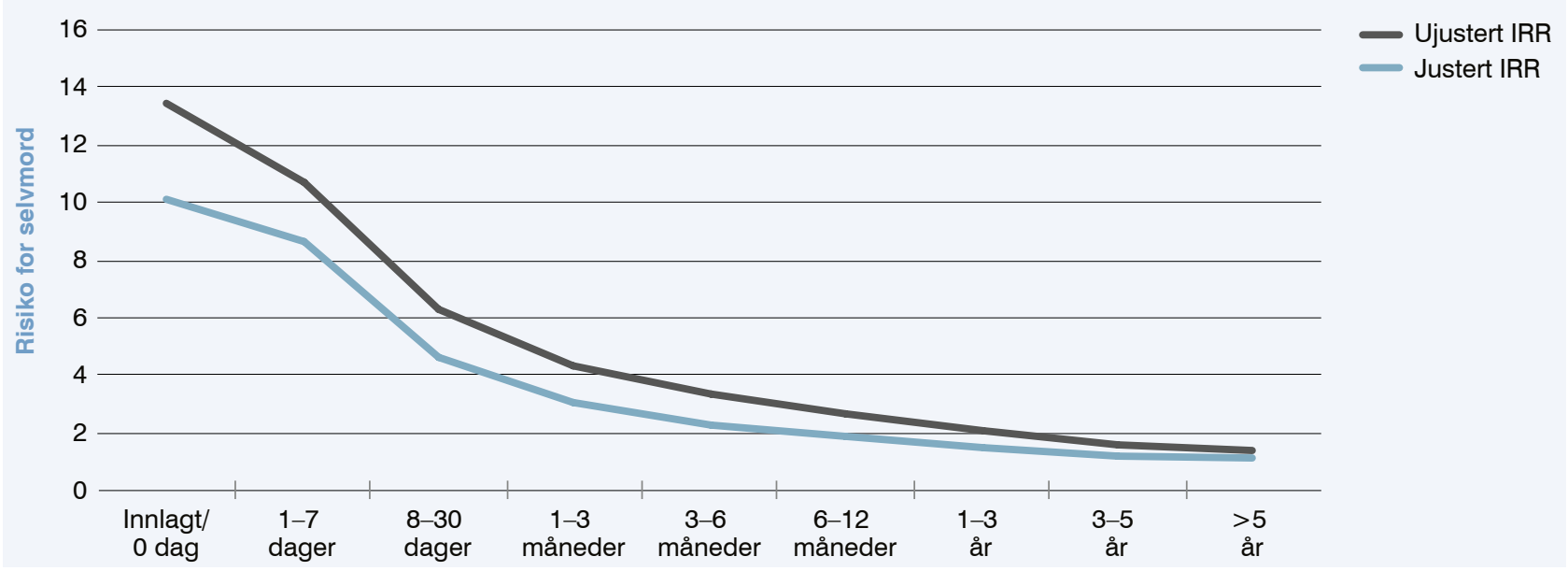

* Justert IRR (insidensrateratio) var justert for psykiske sykdommer, inntekt, sivilstatus, bosted og statsborgerskap. (Kilde: Qin P. et al., 2013)

\section{FIGUR 2. Selvmordsrisiko i forhold til antall sykdommer}

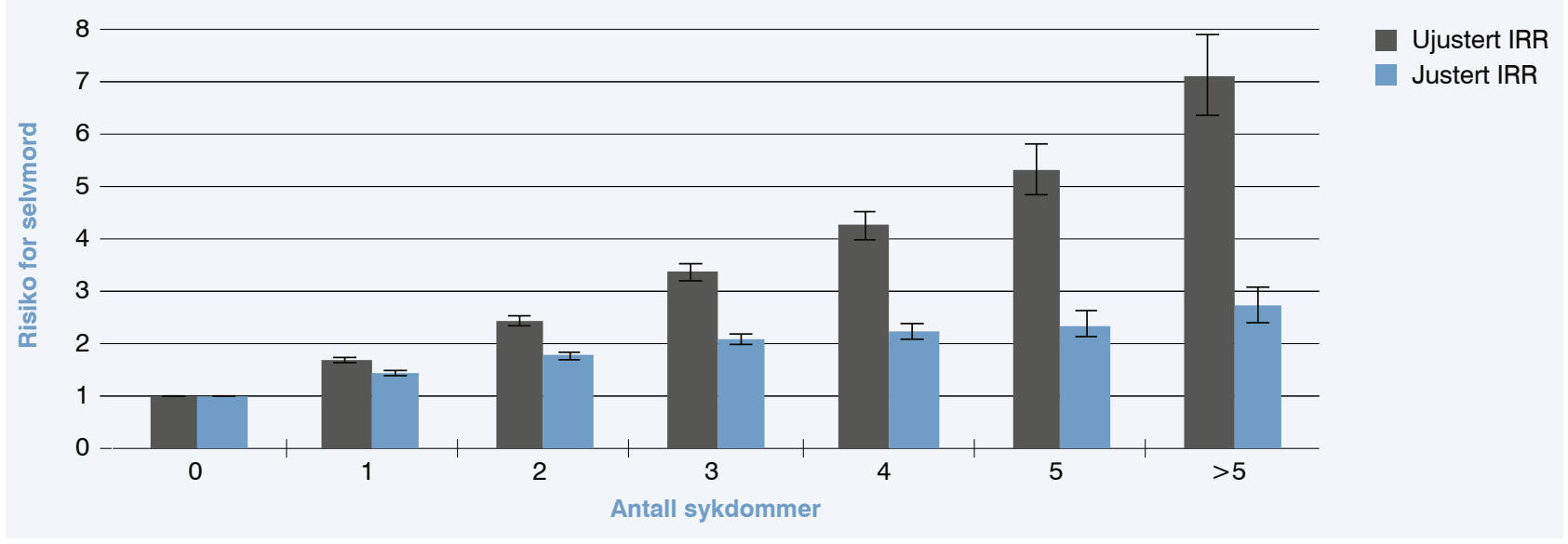


Selvmordsraten er forhøyet blant personer med alvorlige fysiske sykdommer. Raten kan være enda høyere enn det som fremgår av rapportene, fordi legen kan oppgi en potensielt dødelig somatisk sykdom som dødsårsak istedenfor selvmord.

Selvmordsrisikoen øker særlig for pasienter som nylig har fått en alvorlig diagnose, nylig er utskrevet fra sykehus eller har flere sykehusinnleggelser bak seg, og for pasienter med flere samtidige sykdommer.

Den økte selvmordsrisikoen gjelder særlig hvis pasienten får økende eller mer kroniske smerter eller dersom funksjonsnivå og autonomi svekkes.

Personer med somatisk sykdom som dør ved selvmord har særlig hyppig hatt stemningslidelser, primært depresjon, eller rusmisbrukslidelser.

Selvmordsrisiko er særlig forhøyet når man blir rammet av både fysisk og psykisk sykdom omtrent samtidig. Utviklingen av en psykisk lidelse etter fysisk sykdom kan akselerere risikoen for å dø av selvmord. Funnene understreker betydningen av å integrere selvmordsforebygging $\mathrm{i}$ sykehusbehandling og $\mathrm{i}$ generell medisinsk praksis. Det er viktig å diagnostisere og behandle sekundære psykiske problemer blant pasienter med somatiske lidelser.

Man kan ikke regne med at pasienter med somatisk sykdom spontant vil bringe psykiske problemer opp i samtalen på legekontoret. Derfor må legen rutinemessig undersøke om pasienten har psykisk lidelse i tillegg til den somatiske.

kontrolleres for (Christensen et al., 2007; P. Qin et al., 2013; Webb et al., 2012). Dette får særlig betydning for pasienter med fysisk komorbiditet og som har hatt flere sykehusinnleggelser for fysisk sykdom (P. Qin et al., 2013). Dette understreker betydningen av å diagnostisere og behandle sekundære psykiske problemer blant pasienter med somatiske lidelser.

Generelt oker somatisk sykdom risikoen for selvmord mer hos personer uten psykiatrisk lidelse i sykehistorien enn hos dem som har en slik psykiatrisk sykehistorie. Fysisk syke personer som også er behandlet for psykiske lidelser, kan ha fått mer oppmerksomhet rundt mulig selvmordsatferd enn personer som aldri har hatt noen sykehuskontakt på grunn av psykiske problemer. På den annen side kan pasienter som ikke har hatt kontakt med psykiske helsevernstienester lide av psykiske problemer som ikke er blitt diagnostisert eller behandlet. Dette kan bidra til å forklare den relativt sterke effekten av somatiske sykdommer hos pasienter som ikke har en registrert historie med psykisk sykdom (P. Qin et al., 2014; Strid et al., 2014).

Det er viktig å vite at selvmordsrisikoen er særlig sterkt forhøyet når man blir rammet av både fysisk og psykisk sykdom omtrent samtidig, uansett hva som kommer først (P. Qin et al., 2014). Det er også klinisk viktig at utvikling av en psykisk lidelse etter diagnostisering av fysisk sykdom kan akselerere risikoen for å dø av selvmord (P. Qin et al., 2014). Tilstedeværelsen eller utviklingen av psykiske lidelser kan være en konsekvens av forverring av fysisk sykdom, og underliggende psykiske lidelser kan også føre til dårligere behandlingsresultater og lavere livskvalitet for pasientene, som i sin tur oker risikoen for selvmord.

\section{Kliniske implikasjoner}

Den sterke sammenhengen mellom fysiske sykdommer og selvmordsrisiko som er vist i mange studier understreker viktigheten av å diagnostisere og behandle psykiske helseproblemer blant pasienter med fysiske sykdommer. Dette er særlig nødvendig for pasienter som nylig har fått en alvorlig diagnose, nylig er utskrevet fra sykehus eller har flere sykehusinnleggelser bak seg, for pasienter med tilstedeværelse av flere samtidige fysiske sykdommer, for kvinner og eldre, og når psykiske problemer debuterer etter at pasienten har fått en somatisk lidelse. Funnene viser behovet for å integrere selvmordsforebygging i somatisk sykehusbehandling og i generell medisinsk praksis. Det er også viktig at pasienter med fysiske sykdommer opprettholder hyppig kontakt med fastlege etter utskrivning fra sykehuset. Dette gir muligheter for både gientatt risikovurdering og iverksettelse av forebyggende tiltak.

Tradisjonelt har somatiske og psykiske lidelser blitt behandlet hver for seg, og behandlingen har av og til vært mer fokusert på den somatiske tilstanden enn på pasienten. Behandlingen av pasienter med komorbide somatiske og psykiske lidelser kan lett mislykkes dersom man ikke ivaretar hele mennesket. For å kunne oppnå dette må behandlingen av psykiske lidelser være en integrert del av behandlingen. Tett samarbeid mellom klinikere og kliniske enheter med ansvar for både somatisk og psykiatrisk behandling vil være nødvendig. Dette er viktig ikke bare for å forebygge selvmord, men for å kartlegge psykiske helseproblemer som det er mulig å få hielp for, og som vil gi et bedre samlet behandlingstilbud til pasientene.

Hensiktsmessige lokale tjenester må være tilgiengelige for å møte de medisinske, følelsesmessige og praktiske behovene til mennesker med fysisk sykdom. Klinikere bør få opplæring i å kjenne risikofaktorer for selvmord og tilrettelegge tidlig henvisning til psykisk helsevern. Diagnose og behandling av psykiske problemer i en tidlig fase gir muligheter for å hindre at problemene blir så store at de eventuelt fører til selvmordsatferd.

Levert: 14.12.16 - Revidert: 20.03.17 - Godkjent: 22.03.17 


\section{LITTERATUR}

Allebeck, P., Bolund, C. \& Ringback, G. (1989). Increased suicide rate in cancer patients. A cohort study based on the Swedish Cancer-Environment Register. I.Clin.Epidemiol., 42(7), 611-616.

Bronnum-Hansen, H., Stenager, E., Nylev, S. E., \& Koch-Henriksen, N. (2005). Suicide among Danes with multiple sclerosis. J.Neurol.Neurosurg. Psychiatry., 76(10), 1457-1459.

Christensen, I., Vestergaard, M., Mortensen, P. B., Sidenius, P., \& Agerbo, E. (2007). Epilepsy and risk of suicide: a population-based case-control study. Lancet Neurol., 6(8), 693-698.

Eriksson, M., Glader, E. L., Norrving, B., \& Asplund, K. (2015). Poststroke suicide attempts and completed suicides: a socioeconomic and nationwide perspective. Neurology, 84(17), 1732-1738. doi:10.1212/wnl.0000000000001514

Fang, F., Fall, K., Mittleman, M. A., Sparen, P., Ye, W., Adami, H. O., \& Valdimarsdottir, U. (2012). Suicide and cardiovascular death after a cancer diagnosis. N Engl I Med, 366(14), 1310-1318. doi:10.1056/NE/Moa1110307

Fassberg, M. M., Cheung, G., Canetto, S. S., Erlangsen, A., Lapierre, S., Lindner, R., ... Waern, M. (2015). A systematic review of physical illness, functional disability, and suicidal behaviour among older adults. Aging Ment Health, 1-29. doi:10.1080/13607863.2015.1083945

Fredrikson, S., Cheng, Q., Jiang, G. X., \& Wasserman, D. (2003). Elevated suicide risk among patients with multiple sclerosis in Sweden. Neuroepidemiology., 22(2), 146-152.

Gradus, I. L., Qin, P., Lincoln, A. K., Miller, M., Lawler, E., Sorensen, H. T. \& Lash, T. L. (2010). Inflammatory bowel disease and completed suicide in Danish adults. Inflamm.Bowel.Dis., 16(12), 2158-2161.

Hem, E., Loge, I. H., Haldorsen, T., \& Ekeberg, O. (2004). Suicide risk in cancer patients from 1960 to 1999. Journal of Clinical Oncology, 22(20), 4209-4216. doi:10.1200/ic0.2004.02.052

Iia, C. X., Mehlum, L., \& Qin, P. (2012). AIDS/HIV infection, comorbid psychiatric illness, and risk for subsequent suicide: a nationwide register linkage study. I Clin Psychiatry, 73(10), 1315-1321. doi:10.4088/ICP.12mo7814

Larsen, K. K., Agerbo, E., Christensen, B., Sondergaard, I., \& Vestergaard, M. (2010). Myocardial infarction and risk of suicide: a population-based case-control study. Circulation., 122(23), 2388-2393.

Paulsen, I. S., Hoth, K. F., Nehl, C., \& Stierman, L. (2005). Critical periods of suicide risk in Huntington's disease. Am.J.Psychiatry., 162(4), 725-731.

Qin, P. (2016). Selvmordsatferd ved fysiske sykdommer. In Ø. E. o. E. Hem (Ed.), Praktisk selvmordsforebygging (1. utgave ed., pp. 108-116). Oslo: Gyldendal Akademisk.

Qin, P., Hawton, K., Mortensen, P. B., \& Webb, R. (2014). Combined effects of physical illness and comorbid psychiatric disorder on risk of suicide in a national population study. Br I Psychiatry. doi:10.1192/bip.bp.113.128785
Qin, P., Mortensen, P. B., Waltoft, B. L., \& Postolache, T. T. (2011). Allergy is associated with suicide completion with a possible mediating role of mood disorder - a population-based study. Allergy., 66(5), 658-664.

Qin, P., Webb, R., Kapur, N., \& Sorensen, H. T. (2013). Hospitalization for physical illness and risk of subsequent suicide: a population study. I Intern Med, 273(1), 48-58. doi:10.1111/i.1365-2796.2012.02572.x

Stenager, E. N., Wermuth, L., Stenager, E., \& Boldsen, I. (1994). Suicide in patients with Parkinson's disease. An epidemiological study. Acta Psychiatr. Scand., 90(1), 70-72.

Storm, H. H., Christensen, N., \& Jensen, O. M. (1992). Suicides among Danish patients with cancer: 1971 to 1986. Cancer, 69(6), 1507-1512.

Strid, I. M., Christiansen, C. F., Olsen, M., \& Qin, P. (2014). Hospitalisation for chronic obstructive pulmonary disease and risk of suicide: a population-based case-control study. BMI Open, 4(11), eoo6363. doi:10.1136/bmiopen-2014-006363

Teasdale, T. W., \& Engberg, A. W. (2001). Suicide after a stroke: a population study. I Epidemiol.Community Health, 55(12), 863-866.

Timonen, M., Viilo, K., Hakko, H., Sarkioja, T., Ylikuliu, M., Meyer-Rochow, V. B., ... Rasanen, P. (2003). Suicides in persons suffering from rheumatoid arthritis. Rheumatology.(Oxford). 42(2), 287-291.

Tseng, C. H. (2004). Mortality and causes of death in a national sample of diabetic patients in Taiwan. Diabetes Care., 27(7), 1605-16o9.

Vyssoki, B., Gleiss, A., Rockett, I. R., Hackl, M., Leitner, B., Sonneck, G., \& Kapusta, N. D. (2015). Suicide among 915.303 Austrian cancer patients: who is at risk? I Affect Disord, 175, 287-291. doi:10.1016/i.jad.2015.01.028

Wasserman, L., Shaw, T., Vu, M., Ko, C., Bollegala, D., \& Bhalerao, S. (2008). An overview of traumatic brain injury and suicide. Brain Ini., 22(11), 811-819.

Webb, R. T., Kontopantelis, E., Doran, T., Qin, P., Creed, F., \& Kapur, N. (2012). Suicide risk in primary care patients with major physical diseases: a case-control study. Arch.Gen.Psychiatry., 69(3), 256-264.

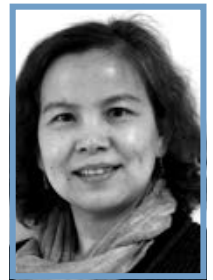

PING QIN er professor, dr.med., spesialist i psykiatrisk epidemiologi ved NSSF, Institutt for klinisk medisin, Universitetet i Oslo. Hun er gruppeleder av registerforskning på selvmord og villet egenskading. 